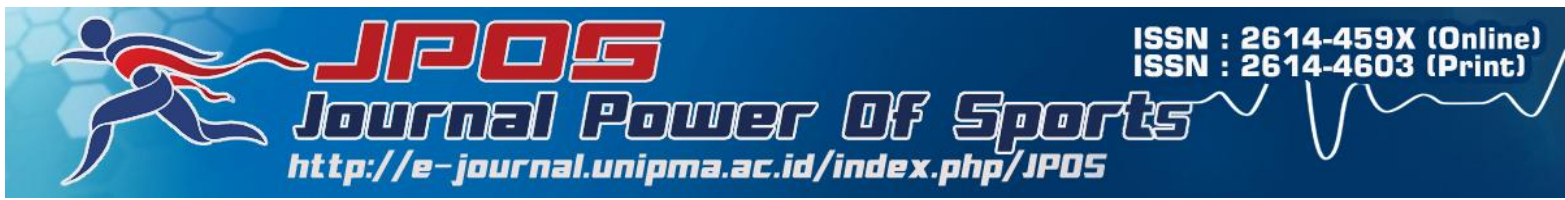

\title{
Analisis hubungan faktor kondisi fisik dominan dengan keterampilan poomsae atlet taekwondo putri Kabupaten Ngawi
}

\author{
Andy Widhiya Bayu Utomo \\ Program Studi Pendidikan Jasmani, STKIP Modern Ngawi, Indonesia \\ Email: andystkipmodern@gmail.com
}

Received: 25 Mei 2018. Accepted: 8 Agustus 2018. Published: 31 Agustus 2018

\begin{abstract}
Abstrak
Upaya pencapaian prestasi olahraga taekwondo dapat dilakukan dengan peningkatan pembinaan di daerah salah satunya yaitu di Kabupaten Ngawi, dimana pencapaian prestasi taekwondo khususnya poomsae masih rendah. Salah satu upaya peningkatan pencapaian prestasi dapat dilakukan dengan meningkatkan kondisi fisik atlet. Kondisi fisik yang baik akan menghasilkan keterampilan yang optimal. Penelitian ini bertujuan menganalisis hubungan faktor kondisi fisik dominan meliputi fleksibilitas, keseimbangan, koordinasi dan power otot tungkai dengan keterampilan poomsae atlet taekwondo putri serta mengetahui seberapa besar kontribusinya. Penelitian ini menggunakan jenis penelitian observasional analitik dengan pendekatan cross sectional. Populasi penelitian ini adalah seluruh atlet taekwondo di Kabupaten Ngawi sebanyak 74 atlet. Teknik pengambilan sampel yaitu purposive sampling dengan sampel sebanyak 32 orang. Teknik pengumpulan data dengan tes dan pengukuran meliputi data komponen fleksibilitas, keseimbangan, koordinasi, power otot tungkai dan keterampilan poomsae. Analisis data dengan korelasional regresi berganda. Skor fleksibilitas, keseimbangan, koordinasi dan power otot tungkai atlet poomsae putri Kabupaten Ngawi paling banyak yaitu pada kategori sedang. Terdapat hubungan positif yang signifikan antara fleksibilitas, keseimbangan, koordinasi dan power otot tungkai dengan keterampilan poomsae. Kontribusi masing-masing variabel terhadap keterampilan poomsae yaitu fleksibilitas $30,7 \%$, keseimbangan $16,8 \%$, koordinasi $68,9 \%$ dan power otot tungkai $42,6 \%$. Secara simultan fleksibilitas, keseimbangan, koordinasi dan power otot tungkai memberikan kontribusi sebesar 75,9\% terhadap keterampilan poomsae.
\end{abstract}

Kata Kunci: kondisi fisik; poomsae; atlet taekwondo putri.

\section{Correlation analysis of dominant physical conditions factor with poomsae skills of female taekwondo athlete in Ngawi Regency}

\section{Abstract}

Attainment effort of taekwondo performance can be done with improvement of coaching in one area such as in Ngawi Regency which has taekwondo performance especially poomsae is still low. One of the efforts to improve performance is improve the physical conditon of 
athlete. Good physical conditions will result in optimal skills. The objectives of this research are analyze the correlation of dominant physical conditons factor such as flexibility, balance, coordination, and limb muscle power to the poomsae skills of the female taekwondo athlete and to what extent their contributions are. This research used the observational analytical method with the cross-sectional design. Its population was all of the taekwondo athlete as many as 74 in Ngawi Regency. The samples of research consisted of 32 female taekwondo athlete with sampling technique used purposive sampling. The data of research were collected through the test and measurement of the components of flexibility, balance, coordination, limb muscle power, and poomsae skills and analyzed by using the the multiple regression and correlation analysis. The female taekwondo athlete in Ngawi Regency have a score of flexibility, balance, coordination and limb muscle power at most is midle category. There is a positive and significant correlation of the flexibility, balance, coordination and limb muscle power to the poomsae skills of the female taekwondo athlete. The contributions of each component to the poomsae skills were 30.7\%, 16.8\%, 68.9\%, 63.7\%, and $42.6 \%$, respectively. Simultaneously, the components of the flexibility, balance, coordination, and limb muscle power contribute by $75,9 \%$ to the poomsae skills.

Key Words: physical conditions; poomsae; female taekwondo athlete.

How To Cite : Utomo, A. W. B. (2018). Analisis hubungan faktor kondisi fisik dominan to APA Style dengan keterampilan poomsae atlet taekwondo putri Kabupaten Ngawi. JPOS (Journal Power Of Sports), 1 (2), 23-29.

\section{PENDAHULUAN}

Prestasi merupakan tujuan yang taekwondo adalah olahraga beladiri yang berasal dari Korea yang mempunyai arti yaitu seni/cara mendisiplinkan diri dengan menggunakan teknik kaki dan tangan kosong. Materi terpenting dalam berlatih taekwondo adalah poomsae, kyukpa dan kyoruki. Teknik dasar yang harus dikuasai seorang taekwondoin (Hu-seup Song dan Jongo Kim (1986:39-61) dalam Suyardi, Y (2002)) yaitu kuda-kuda (Seogi), teknik serangan (Kongkyok Kisul) seperti pukulan (Jierugi), sabetan (Chigi), tusukan (Chierugi) dan tendangan (Chagi), tangkisan (Makki), bagian tubuh yang menjadi sasaran (Keup So), bagian tubuh yang digunakan untuk menyerang atau bertahan.

Menurut Suryadi, (2002) dalam Andy (2016) menyebutkan bahwa tiga materi terpenting dalam berlatih taekwondo, yaitu Poomsae atau rangkaian jurus adalah rangkaian teknik gerakan dasar serangan dan pertahanan diri yang dilakukan melawan musuh yang imajiner dengan mengikuti diagram tertentu, Kyukpa atau teknik pemecahan benda keras adalah latihan teknik dengan memakai sasaran/obyek benda mati, untuk mengukur kemampuan dan ketepatan tekniknya serta kyoruki atau pertarungan adalah latihan yang mengaplikasikan teknik gerakan dasar atau poomsae, dimana dua orang yang bertarung saling mempraktekkan teknik serangan dan teknik pertahanan diri.

Kabupaten Ngawi merupakan salah satu Kabupaten yang mengembangkan olahraga taekwondo. Tempat latihan taekwondo (dojang) di Kabupaten Ngawi berjumlah 13 dojang, sedangkan pusat latihan atlet berpusat di dua dojang yaitu di Kecamatan Ngawi dan Walikukun. Prestasi yang ditunjukkan dari Atlet taekwondo Kabupaten Ngawi masih rendah, sehingga masih diperlukan peningkatan pembinaan prestasi agar lebih maksimal. Salah satu upaya mencapai prestasi yang baik dalam olahraga taekwondo yaitu atlet harus memiliki kondisi fisik yang baik, karena fisik merupakan modal dasar dalam mencapai 
keterampilan yang optimal (Andy, 2016). Tanpa adanya kondisi fisik yang baik dari seseorang berarti akan sulit untuk menjalankan program latihan, sehingga keterampilan pun akan sulit tercapai.

Menurut M. Sajoto (1988:57) dalam Sembiring (2013:9), "salah satu faktor penentu dalam mencapai prestasi olahraga adalah terpenuhinya komponen fisik, yang terdiri dari kekuatan (strength), kecepatan (speed), kelincahan (agility), koordinasi (coordination), daya tahan (endurance), daya ledak otot (muscular power), fleksibilitas (flexibility), keseimbangan (balance), ketepatan (accuracy) dan reaksi (reaction). Komponen kondisi fisik dominan yang berhubungan dengan olahraga taekwondo khususnya poomsae yaitu fleksibilitas, keseimbangan, koordinasi dan power otot tungkai.

Andy (2016) menyebutkan bahwa pada saat tes keterampilan poomsae di Dojang taekwondo Kabupaten Ngawi, kemampuan atlet menurun pada akhir poomsae seperti kecepatan tendangan, keakuratan gerakan dan juga kelelahan yang berlebihan. Adanya fakta tersebut membuktikan bahwa perlu adanya perhatian lebih untuk meningkatkan kondisi fisik atlet, selain perhatian untuk penguasaan teknik keterampilan saja.

\section{METODE PENELITIAN}

\section{A. Analisis Univariat}

Tabel 1. Data Fleksibilitas

\begin{tabular}{|c|c|c|c|}
\hline \multicolumn{2}{|c|}{ Variabel Fleksibilitas } & \multirow{2}{*}{$\mathrm{n}$} & \multirow{2}{*}{$\%$} \\
\hline Nilai & Kategori & & \\
\hline$>19,5$ & Baik Sekali (BS) & - & - \\
\hline $17,0-19,0$ & Baik (B) & 8 & 25 \\
\hline $14,5-16,5$ & Sedang $(\mathrm{S})$ & 14 & 43,7 \\
\hline $12,5-14,0$ & Kurang (K) & 10 & 31,3 \\
\hline \multirow[t]{2}{*}{$>12,0$} & Kurang Sekali (KS) & - & - \\
\hline & Total & 32 & 100 \\
\hline
\end{tabular}

Penelitian ini dilaksanakan di Dojang Kabupaten Ngawi pada bulan Januari-Maret 2018 dengan menggunakan jenis penelitian observasional analitik dan rancangan penelitian cross sectional.

Populasi penelitian ini adalah seluruh atlet taekwondo di dojang Kabupaten Ngawi sebanyak 74 atlet. Teknik pengambilan sampel yaitu purposive sampling dengan karakteristik sampel yaitu atlet taekwondoin putri, menyandang sabuk hijau, biru dan merah serta kelompok pra-junior dan junior sehingga diperoleh sampel sebanyak 32 orang.

Teknik pengumpulan data dengan tes dan pengukuran meliputi data komponen fleksibilitas, keseimbangan, koordinasi, power otot tungkai dan keterampilan poomsae. Tes yang dilakukan pada masing-masing komponen yaitu tes sit and reach (fleksibilitas), stork stand (keseimbangan), soccer wall volley test (koordinasi), standing broad jump (power otot tungkai) dan taeguk 4 (keterampilan poomsae).

Analisis data menggunakan teknik analisis korelasional regresi berganda dengan program SPSS versi 24.0 meliputi analisis univariat dan bivariat (uji korelasional dan uji regresi linier berganda). Analisis univariat akan ditampilkan pada tabel 1-5 berikut. 
Tabel 2. Data Keseimbangan

\begin{tabular}{|c|c|c|c|}
\hline \multicolumn{2}{|c|}{ Variabel Keseimbangan } & \multirow{2}{*}{$\mathrm{n}$} & \multirow{2}{*}{$\%$} \\
\hline Nilai & Kategori & & \\
\hline$>50$ & Baik Sekali (BS) & - & - \\
\hline $41-50$ & Baik (B) & 5 & 15,6 \\
\hline $31-40$ & Sedang $(S)$ & 18 & 56,3 \\
\hline $20-30$ & Kurang $(\mathrm{K})$ & 9 & 28,1 \\
\hline \multirow[t]{2}{*}{$<20$} & Kurang Sekali (KS) & - & - \\
\hline & Total & 32 & 100 \\
\hline
\end{tabular}

Tabel 3. Data Koordinasi

\begin{tabular}{|c|c|c|c|}
\hline \multicolumn{2}{|c|}{ Variabel Koordinasi } & \multirow{2}{*}{$\mathrm{n}$} & \multirow{2}{*}{$\%$} \\
\hline Nilai & Kategori & & \\
\hline$>35$ & Baik Sekali (BS) & - & - \\
\hline $30-35$ & Baik (B) & 3 & 9,4 \\
\hline $20-29$ & Sedang (S) & 22 & 68,8 \\
\hline $15-19$ & Kurang (K) & 7 & 21,8 \\
\hline \multirow[t]{2}{*}{$<15$} & Kurang Sekali (KS) & - & - \\
\hline & otal & 32 & 100 \\
\hline
\end{tabular}

Tabel 4. Data Power Otot Tungkai

\begin{tabular}{|c|c|c|c|}
\hline \multicolumn{2}{|c|}{ Variabel Power Otot Tungkai } & \multirow{2}{*}{$\mathrm{n}$} & \multirow{2}{*}{$\%$} \\
\hline Nilai & Kategori & & \\
\hline$>2,25$ & Baik Sekali (BS) & - & - \\
\hline $2,25-2,14$ & Baik (B) & 7 & 21,9 \\
\hline $2,14-2,03$ & Sedang (S) & 16 & 50 \\
\hline $2,03-1,07$ & Kurang (K) & 9 & 28,1 \\
\hline \multirow[t]{2}{*}{$<1,07$} & Kurang Sekali (KS) & - & - \\
\hline & Total & 32 & 100 \\
\hline
\end{tabular}

Tabel 5. Data Keterampilan Poomsae

\begin{tabular}{ccc}
\hline Variabel Keterampilan Poomsae & N & $\%$ \\
\hline $9-10$ & - & - \\
$8-8,9$ & 5 & 15,6 \\
$7-7,9$ & 14 & 43,8 \\
$6-6,9$ & 13 & 40,6 \\
$5-5,9$ & - & - \\
\hline Total & 32 & 100
\end{tabular}

Dari tabel 1 dapat diketahui bahwa atlet poomsae putri paling banyak mempunyai nilai fleksibilitas kategori sedang yaitu 14 atlet $(43,7 \%)$. Dari tabel 2 dapat diketahui bahwa atlet poomsae putri paling banyak mempunyai nilai keseimbangan kategori sedang yaitu 18 atlet $(56,3 \%)$. Dari tabel 3 dapat diketahui bahwa atlet poomsae putri paling banyak mempunyai nilai koordinasi kategori sedang yaitu 22 atlet $(68,8 \%)$. Dari tabel 4 dapat diketahui bahwa atlet poomsae putri paling banyak mempunyai nilai power otot tungkai kategori sedang yaitu 16 atlet (50 
$\%)$. Dari tabel 5 dapat diketahui bahwa keterampilan poomsae atlet putri paling banyak yaitu pada poin $7-7,9$ sebanyak 14 atlet $(43.8 \%)$.

\section{B. Analisis Bivariat}

Uji F

Tabel 6. Hasil uji F

\begin{tabular}{llccc}
\hline \multicolumn{1}{c}{ Persamaan } & F Hitung & F Tabel & Sig \\
\hline $\begin{array}{l}\text { Fleksibilitas, Keseimbangan, } \\
\text { Power Otot Tungkai }\end{array}$ & 35,168 & 2,327 & .000 \\
\hline
\end{tabular}

Uji t

Tabel 7. Hasil uji t

\begin{tabular}{lccc}
\hline \multicolumn{1}{c}{ Variabel } & Value $(r)$ & Sig. $p$ & Kesimpulan \\
\hline Fleksibilitas & .526 & 0.000 & Korelasi Positif signifikan \\
Keseimbangan & .437 & 0.000 & Korelasi Positif signifikan \\
Koordinasi & .789 & 0,000 & Korelasi Positif signifikan \\
Power Otot Tungkai & .624 & 0.000 & Korelasi Positif signifikan \\
\hline
\end{tabular}

Uji $\mathrm{R}^{2}$

Tabel 8. Hasil Uji R ${ }^{2}$

\begin{tabular}{lcc}
\hline \multicolumn{1}{c}{ Persamaan } & $\mathrm{R}$ & $\mathrm{R}$ Square \\
\hline Fleksibilitas & 0,526 & 0,307 \\
\hline Keseimbangan & 0,437 & 0,168 \\
\hline Koordinasi & 0,789 & 0,689 \\
\hline Power Otot Tungkai & 0,624 & 0,426 \\
\hline $\begin{array}{l}\text { Fleksibilitas, keseimbangan, koordinasi dan power } \\
\text { otot tungkai }\end{array}$ & 0,853 & 0,759 \\
\hline
\end{tabular}

Analisis korelasi

Tabel 9. Hasil analisis korelasi

\begin{tabular}{lcc}
\hline \multicolumn{1}{c}{ Persamaan } & $\mathrm{R}$ & $\mathrm{R}$ Square \\
\hline $\begin{array}{l}\text { Fleksibilitas, Keseimbangan, Koordinasi, Power Otot } \\
\text { Tungkai }\end{array}$ & 0,796 & 0,732 \\
\end{tabular}

Berdasarkan tabel 6 dapat diketahui bahwa $\mathrm{F}$ hitung $>\mathrm{F}$ tabel $(35,168>2,327)$ dengan tingkat signifikansi $0,000<0,05$, sehingga $\mathrm{H}_{0}$ ditolak. Dengan demikian dapat disimpulkan bahwa secara simultan variabel fleksibilitas, keseimbangan, koordinasi dan power otot tungkai memiliki pengaruh yang sangat signifikan terhadap variabel keterampilan poomsae.

Berdasarkan tabel 7 , semua variabel mempunyai nilai $p 0,000(p<0,05)$ maka Ho ditolak sehingga ada hubungan/korelasi yang signifikan antara semua variabel dengan keterampilan poomsae.
Tabel 8 menunjukkan bahwa berdasarkan nilai $\mathrm{R}^{2}$ masing-masing variabel, kontribusi tiap variabel terhadap keterampilan poomsae yaitu fleksibilitas $30,7 \%$, keseimbangan $16,8 \%$, koordinasi $68,9 \%$ dan power otot tungkai $42,6 \%$. Persentase pengaruh/kontribusi variabel fleksibilitas, keseimbangan, koordinasi dan power otot tungkai terhadap variabel keterampilan poomsae sebesar 75,9\%.

Berdasarkan tabel 9, diperoleh nilai $\mathrm{R}$ sebesar 0,796. Hal ini menunjukkan bahwa terjadi hubungan yang kuat antara variabel fleksibilitas, keseimbangan, koordinasi dan power otot tungkai 
terhadap variabel keterampilan poomsae. Karena nilai koefisien korelasi (R) menunjukkan nilai 0,732 berada antara $0,60-0,799$.

\section{HASIL DAN PEMBAHASAN}

1. Fleksibilitas

Terdapat hubungan yang signifikan antara fleksibilitas terhadap keterampilan poomsae dengan nilai $p=$ $0,000(p<0,05)$ dan kontribusi sebesar $30,7 \%$. Fleksibilitas merupakan salah komponen dasar dalam melatih kondisi fisik agar keterampilan poomsae seorang atlet taekwondoin akan meningkat, karena dengan fleksibilitas yang baik, taekwondoin dapat menggerakkan tubuh dan bagian-bagian tubuh dalam satu ruang gerak yang seluas mungkin, tanpa mengalami, menimbulkan cidera pada persendian dan otot di sekitar persendian tersebut.

2. Keseimbangan

Terdapat hubungan yang signifikan antara keseimbangan terhadap keterampilan poomsae dengan nilai $p=0,000(p<0,05)$ dan kontribusi sebesar $16,8 \%$. Dalam poomsae, pada setiap gerakannya meliputi tendangan, pukulan dan tangkisan. Jika dalam bermain poomsae, keseimbangan taekwondoin tidak tepat maka akan mengacaukan gerakan poomsae selanjutnya atau gerakan poomsae menjadi tidak akurat.

3. Koordinasi

Terdapat hubungan yang signifikan antara koordinasi terhadap keterampilan poomsae dengan nilai $p=$ $0,000(p<0,05)$ dan kontribusi sebesar $68,9 \%$. Unsur koordinasi sangat diperlukan dalam penguasaan hampir semua cabang olahraga seperti halnya poomsae taekwondo, yang didalam penilaian berdasarkan peraturan WTF memiliki kriteria berupa keterampilan, akurasi dan lintas gerakan, kecepatan gerakan yang didalamnya membutuhkan koordinasi dari mata kaki sebagai pengontrol gerakan tersebut.

\section{Power Otot Tungkai}

Terdapat hubungan yang signifikan antara power otot tungkai terhadap keterampilan poomsae dengan nilai $p=0,000(p<0,05)$ dan kontribusi sebesar $42,6 \%$. Power otot tungkai sangat dibutuhkan dalam sikap kudakuda yang sebagian besar ada dalam gerakan poomsae. Selain itu, untuk mencapai tendangan saat bermain poomsae, harus ada power otot tungkai untuk mengangkat paha dan menolak pada saat menendang. Seorang taekwondoin harus mempunyai kaki yang kuat, pergelangan kaki yang kuat, lutut yang kuat dan tungkai yang kuat agar dapat memikul badan yang berat.

5. Hubungan antara fleksibilitas, keseimbangan, koordinasi dan power otot tungkai dengan keterampilan poomsae

Secara simultan variabel fleksibilitas, keseimbangan, koordinasi dan power otot tungkai memiliki pengaruh yang sangat signifikan terhadap variabel keterampilan poomsae dengan kontribusi sebesar $75,9 \%$. Secara skematis fleksibilitas, keseimbangan, koordinasi, dan power otot tungkai akan mempengaruhi keterampilan poomsae seorang atlet taekwondo dalam sebuah pertandingan. Power otot menjadi faktor tersendiri sebagai pemicu sebuah gerakan yang dibutuhkan dalam olahraga taekwondo, daya ledak yang kuat akan menambah daya serang, selain juga untuk merubah posisi dari taekwondoin. Keseimbangan yang baik dalam taekwondo, menciptakan keselarasan gerakan yang ritmik tanpa jatuh pada saat terjadi perubahan garis sumbu tubuh, hal ini sejalan dengan salah satu prinsip dari taekwondo yang mengatakan bahwa taekwondo adalah salah satu bentuk 
keindahan gerak, keefisienan dan keefektifan dari teknik bertahan dan menyerang. Sedangkan koordinasi berhubungan dengan kemampuan indera tubuh dalam mengatur dan mengontrol gerakan yang akan dilakukan, terkait juga dalam hal ini tentang keseimbangan gerakan yang dilakukan, baik dari sistem motorik dan sensori tubuh.

\section{KESIMPULAN}

1. Skor fleksibilitas, keseimbangan, koordinasi dan power otot tungkai atlet poomsae putri Kabupaten Ngawi paling banyak yaitu pada kategori sedang.

2. Terdapat hubungan positif yang signifikan antara fleksibilitas, keseimbangan, koordinasi dan power otot tungkai terhadap keterampilan poomsae atlet taekwondo putri Kabupaten Ngawi.

3. Terdapat hubungan positif yang signifikan antara fleksibilitas, keseimbangan, koordinasi, dan power otot tungkai dengan keterampilan poomsae atlet taekwondo putri Kabupaten Ngawi.

\section{DAFTAR PUSTAKA}

Abrahamova, D., Hlavacka, F. (2008). Age-Related Changes of Human Balance during Quiet Stance. Physiological Research. Prague: Institute of Physiology v.v.i., Academy of Sciences of the Czech Republic.

Utomo, A. W. B. (2016). Pencapaian Keterampilan Poomsae ditinjau dari Kecepatan, Fleksibilitas, Keseimbangan, Koordinasi, Power Otot Tungkai dan Volume Oksigen Maksimal (Studi Korelasional pada Taekwondoin Putra Kabupaten Ngawi). Tesis. Surakarta. UNS.

Young, K. J. (2009). The Taekwondo Teks Book of Poomsae. Korea: O-sung Publising Company.
Sembiring, R. (2013). Peningkatan Kondisi Fisik Melalui Latihan Circuit Training pada Atlet pada Atlet Taekwondo Putra Junior Sibayak Club Medan Tahun 2013. Medan: UNIMED.

Sharkley, B. J. (2011). Kebugaran dan Kesehatan. Rajawali Sport, Devisi Buku Olahraga \& Kesehatan: PT. Raja Grafindo Persada.

Sugiyono. (2013). Metode Penelitian Pendidikan (Pendekatan Kuantitatif, Kualitatif, dan R\&D). Bandung: Alfa Beta.

Suryadi, Y. (2002). Taekwondo Poomsae Taeguk. Jakarta: Gramedia.

World Taekwondo Federation. (2006). Poomsae Competition Rules and Interpretation. Indonesia: World Taekwondo Federation. 